\title{
Governance Mechanisms as Promoters of Governability: A Political Science Perspective on Institutional Complexity
}

\section{Sjöblom, Stefan Mikael}

Sage

2018

Sjöblom , S M \& Andersson, K W 2018 , Governance Mechanisms as Promoters of Governability: A Political Science Perspective on Institutional Complexity . in T Marsden (ed.) , The SAGE Handbook on Nature . Sage , London , pp. 105-127 . https://doi.org/10.4135/9781473983007.n7

http://hdl.handle.net/10138/326870

https://doi.org/10.4135/9781473983007.n7

unspecified

acceptedVersion

Downloaded from Helda, University of Helsinki institutional repository.

This is an electronic reprint of the original article.

This reprint may differ from the original in pagination and typographic detail.

Please cite the original version. 
Recto running head: Governance Mechanisms as Promoters of Governability (51 characters)

\section{6}

Governance Mechanisms as Promoters of Governability: A Political Science Perspective on Institutional Complexity

\section{Stefan Sjöblom \& Kjell Andersson}

\section{Introduction}

The concept of governability emerged in the 1970s as an exponent of a semi-political movement promoting the idea that modern democracies had become ungovernable because of an overload of public tasks (Crozier et al., 1975). In later years, the focus has been on the dynamics of complex societies, especially the capacity of highly specialized policy fields to resist policy guidance (Kooiman, 2008, p. 172; Mayntz, 1993). Despite differences in interpretations the key issue of the governability concept has been the capacities of the state as a governance agency. Following Kooiman (2008) governability can be defined as 'the overall capacity for governance of any societal entity or system'. Perceived in this way, governability is an ever changing quality, highly dependent on complex interactions between external and internal factors, for example, changes in the environment including natural resource systems, 
the governance structure at hand and the nature of the societal system-to-be-governed, be it a municipality, a policy network, a state or a supranational institution.

The governability concept reflects the growing insight that all societal systems are complex combinations of orders in which a multiplicity of factors and conditions affect the outcome of social processes. These processes are differentiated and nested based on multiple mechanisms, processes and social forces. In this perspective, order cannot be explained by a single governance structure or government logic (Schneider, 2012, p. 139). On the contrary, in such a context rules, actors and agents adapt endogenously over time in order to cope with increasingly complex and diverse demands and environments. What may be high governability at one time may be low governability at another (Kooiman, 2008, p. 173). According to such an understanding of complex societal systems, agents aim at improved fitness through 'the logic of appropriateness'; adjusting their action on the basis of trial and error, feedback and learning. As argued by Schneider $(2012$, p. 137) it is important to note that fitness does not necessarily equate with improved performance. Adaptation is about finding the appropriate solution in a certain context.

Governance theory has, since the 1980s, emerged as a reflection of growing societal complexity, emphasizing international embeddedness, globalization, increasing fragmentation of the state and a loss of policy capacity of public institutions. The perspective has shifted from government towards social complexity and the interactions between government and societal partners (cf. Jacobsson et al., 2015). As the state was 'rolled back' by neoliberal reform, new policy fields such as innovation policies, regional development policies, sustainability policies and climate policies emerged, resting on strong demands for resources from different parts of society. As a consequence, policies are increasingly implemented by new collaborative arrangements and policy instruments operating at a considerable distance from the political center (Jacobsson et al., 2015, p. 12). New forms of co-governance and public policymaking, such as partnerships, democratic networks, projects and deliberative 
fora, rely heavily on collaborative and participatory qualities while also being expected to increase the effectiveness of decision-making processes. A common feature of such governance arrangements and arenas is that organizational flexibility and a low level of formalization is perceived as crucial for dealing effectively with complex governance problems (Rhodes, 1996; Kickert et al., 1997; Pierre, 2012).

Developing effective governance solutions is particularly challenging with respect to social-ecological processes of change. Ecosystems are characterized by dynamism and emergent properties that generate complexity and uncertainty (Dryzek, 1987). The increasing political salience of environmental issues has been driven by long-term development trends, including rising pressures on natural systems from increasingly potent and widespread technologies, growing human population numbers and higher levels of material consumption (Meadowcroft, 2013). Furthermore, much uncertainty results from the unintended consequences of past activities, while global climate change is likely to introduce further complexity and uncertainty into ecosystem futures (Lockwood et al., 2010).

The rise of environmentalism and sustainability concerns is thus one important driver behind contemporary problems of governability. Volatilities are profound and they emerge from different sources. They cannot be dealt with in a conventional top-down fashion, neither can they be solved by a retreat to localism. They demand both short-term and long-term policy action at local, national as well as transnational levels (Sjöblom et al., 2012). Within complex and emergent contexts there is thus a constant need for assessing and reassessing the relationship between governance arrangements and governability. A given order can rarely be explained by a single governance structure or government logic. What may be effective governance in one context may be ineffective in another (Kooiman, 2008, p. 173). Similarly, governance can be a solution, but also a problem. By means of, for example, deregulation, the introduction of soft steering instruments and collaborative structures governance arrangements may enhance flexibility and adaptive capacities, while at the same time 
challenging the institutional stability necessary for ensuring traditional political and administrative authority (Pierre, 2012, p. 187). Although it is common to view change as an organizational response to exogenous forces, complexities may also be generated endogenously as government institutions and other actors are given partially new roles to play in the collaborative governance game (Pierre, 2012; Schneider, 2012).

The purpose of this chapter is to specify the mechanisms and conditions under which collaborative governance arrangements may facilitate, but also challenge, governability in complex institutional contexts. The remainder of the chapter is organized as follows: In the next two sections key drivers of complexity are specified and related to core institutional dimensions affecting the governability of politico-administrative systems. In the subsequent sections selected governance mechanisms are scrutinized as potential solutions to problems of governability.

\section{Drivers of institutional complexity}

From a governance perspective complexity is usually understood as the reduced capabilities for steering and control due to increasing national and supranational dependencies, but also due to an erosion of a 'collective will' and the differentiation of societal demands and interests. Political endeavors are especially susceptible to such developments and thus complexity has become one of the most important points of departure for interpreting societal changes (cf. Dennis, 2007; Laux, 2011). As argued earlier, complexities of a social system can have external as well as internal sources. In this context we would emphasize three drivers of complexity that have been particularly challenging to the governability of contemporary democratic systems. The first one is essentially a matter of scale, which illustrates that complexity cannot be understood only in a structural sense. Contemporary societal problems such as climate change, pollution, food and energy supply, mobility, welfare 
and social security are functionally intertwined to a much greater extent than a few decades ago.

Furthermore, problems and policies are increasingly variable in terms of spatial scales. Regional entities are increasingly perceived as strategic, flexible and dynamic spaces. Territorial boundaries are continuously being reconstructed along different spatial scales (Amin, 1999). Responses to regional problems have become increasingly variable and unpredictable and less attached to predetermined institutional structures. In contemporary spatial planning and policy concepts, such as polycentric development and urban networks, have become catchphrases for the support of territorial cohesion and regional competitiveness (Burger et al., 2014). The development of subnational governance in Europe has been a process of differentiation rather than homogenization. Furthermore, there are considerable developments towards diversity within countries. In some cases, national level data become almost meaningless as they gloss over huge regional variations (Charron, 2013; Hendricks et al., 2011).

In addition to functional and spatial scales, changing temporal scales also pose challenges to the stability of institutional structures. Although there is not necessarily a contradiction between long-term and short-term action, the differentiated time frames of societal problems and the simultaneous quest for just-in-time interventions that characterize high-velocity societies increases the risks for temporal and functional misfits between institutions and the issues in question. By consequence, the temporal dimension of current forms of organizing are significantly more pronounced than ever.

On the one hand, there is a need to develop long-term solutions and strategies within processes that are increasingly open-ended and where the effects of decisions may outlast governments by many generations (cf. Adam, 1995, p. 109; Loorbach, 2010, p. 162). On the other hand, there is a quest for instant action. A global trend with such effects is the technological character of the information society, demanding fast reactions to the extent 
that, some have argued, acceleration becomes a hegemonic imperative of late modernity (Laux, 2011). Another global trend serves as an example of efforts to mitigate the tension between long- and short-term actions, namely the strong emphasis on sustainable development in the aftermath of the 1992 Rio Earth Summit and the Agenda 21 agreement, resulting in a worldwide generation of capacity-building programs, initiatives, partnerships and projects, with the aim to strengthen the ability of local communities and organizations to contribute to sustainable development. Similar developments can be observed in other policy fields. Delimited and focused activities become the strategic imperative for actions in openended processes (Jacobsson et al. 2015).

Another driver behind the increasingly complex and variable governance arrangements is the rigidity of contemporary democratic structures. According to a conventional understanding, it is the task of central government to maintain coordination and to impose a public interest on non-state actors. As the state still is perceived as the guarantor of social order, its actions represent a considerable fear of the inability to secure the rationality of political decisions (cf. Laux, 2011, p. 227). It reacts to dynamism by striving towards stability. Largely determined by the electoral cycles, the dynamics of democratic decision-making has remained essentially unchanged.

Moreover, political action has benefited from technological developments, but only to a limited extent. Unlike key activities of markets or media, political decisions as well as fundamental principles such as openness and transparency demand face-to-face interaction. Given the multi-scalar and temporally differentiated nature of contemporary social problems described above, coordination and synchronization become severe governance problems when demands for political regulation cannot be met in a timely fashion. As convincingly demonstrated by Henning Laux (2011, p. $234 \mathrm{ff}$.) events such as the fall of Lehman Brothers and the world financial crisis illustrate how the decisions of parliamentary systems 
increasingly are reactions to external pressures and events or to decisions made by faster social subsystems such as science, markets or media.

Furthermore, the challenges to representative democracy facing most Western societies including a reduction in long-term civic involvement through representative channels and a stronger preference for more individualized and less formalized mediums for action, presumably strengthen the individual-level inclination for just-in-time action (cf. Hendricks et al., 2011; Norris, 2011). The possibilities for acceleration by means of transforming fundamental democratic principles or parliamentary procedures are rather limited. The option would be enhance coordination, synchronization and strategic agility by introducing new institutional mechanisms and organizational forms at the interface of politics and other social subsystems. This is the third driver behind the increased institutional complexity of the contemporary politico-administrative system, manifested, first, in a strong emphasis on performance management, evaluation and learning but also, second, in the emergence of informal policy instruments and non-bureaucratic forms of organizing societal activities and entities. Projects, partnerships, networks and contractual forms of cooperation are examples of means for increasing the problem-solving and coordinative capabilities of executive systems and for organizing vested interests, stakeholders and expertise on a just-in-time basis. 'The project', especially, has become an organizational archetype not only for accelerated social problem-solving but also for decisiveness, innovation and entrepreneurship, to the extent that project proliferation has been taken into account for a projectification of politics and public sector activities (Godenhjelm et al., 2015; Jensen et al., 2013; Sjöblom et al., 2013). It is important to recognize that the increase in organizational alternatives and governance mechanisms, while inherently positive in its intentions, may also generate undesirable consequences and, in terms of governability, constitute new sources of governmental overload on the output side of the policy cycle (cf. Lewis \& Triantafillou, 2012). Many organizational alternatives and policy instruments are output-focused and may certainly, on 
the one hand, create new solutions to policy problems on a just-in-time basis. On the other hand, they are demanding in terms of compliance, participation, dialog and information. It is thus increasingly important to weight the benefits and costs of various governance solutions.

\section{Societal complexity and the institutional pillars}

From an institutional point of view, complexity can be interpreted as a consequence of the three aforementioned parallel developments: a) multi-scalar societal problems demanding increasingly open-ended and long-term processes; b) essentially unchanged parliamentary systems meaning that decisions placed under multi-scalar pressures are increasingly incompatible with democratic structures (Laux, 2011, p. 233) and by consequence; c) an enforced need to fortify the capacities of the executive systems for strategic agility and justin-time action. The hypothetical dependencies are outlined in Figure 6.1. The results of these developments have been interpreted as a massive desynchronization between the tempo of political decisions and that of social evolution (Laux, 2011, p. 232). The developments have considerable impacts on all essential institutional dimensions of the politico-administrative system.

\section{[TS: Insert Figure 6.1 here]}

Figure 6.1 Temporal differentiation and the sources of legitimacy

In his well-known synthetization of institutional concepts Richard Scott (2008) distinguishes between three institutional pillars, that is, the three key elements that constitute or support institutions, namely regulative, normative and cognitive (Scott, 2008, p. 47 ff.; Thornton et al., 2012, p. $36 \mathrm{ff}$.$) . The regulative pillar refers to rule setting, monitoring and sanctioning activities$ but also more informal ways in which actors pursue their rational interests. The normative pillar stands for the values and norms that specify the moral, prescriptive and evaluative dimension of social activities. The cognitive pillar refers to the shared understanding and logic 
of action, that is, the frames through which identity and meaning are interpreted. Drawing partly on DiMaggio and Powell (1991), Scott aligns each of the pillars with specific, although related, sources of legitimacy and their respective mechanisms: coercive, normative and mimetic isomorphism.

Thus, the regulativepillar rests on legitimacy from conformity with legal requirements, leading, for example, to pressures on organizations for conformity, stemming from government mandate in a common legal environment (cf. Thornton et al., 2012, p. 37). The normative pillar emphasizes conformity to a moral basis, stemming, for example, from science, expert knowledge or professional values. As for the cognitive pillar, legitimacy derives from adopting a common frame of understanding of the situation meaning, for instance, that organizations perceived to be successful are feasible sources of imitation especially in uncertain and competitive environments (DiMaggio \& Powell, 1991).

There are numerous applications for Scott's categorization (see for instance, Thornton et al., 2012) but a further elaboration goes beyond the purpose of this chapter. Our point in this context is simply that increasing complexities may have considerable effects on key institutional mechanisms related to the three dimensions outlined above, that is, mechanisms for reaching conformity with norms, shared values or a shared understanding of societal problems and situations.

As summarized in Table 6.1, the regulative pillar emphasizes mechanisms that affect the inclination among involved actors to adhere to regulative rules. The logic is essentially instrumental. Such approaches are, however, challenged by the increasingly multi-scalar nature of societal problems. The possibilities of reacting to these problems, on a purely instrumental basis, are very limited. Complexities of scale also affect shared values in society, that is, conceptions of the preferred and desirable as well as perceptions of how things should be done (cf. Scott, 2008, p. 54 f.), causing an increasing demand for long-term action and prescriptive guidance, but may also cause increasing conflicts between functional, spatial and 
temporal aspects of policy problems and between increasingly diverse interests. Such changes also have potential consequences for how the actors perceive their roles and especially the goals that guide their actions. Due to the essentially unchanged structure of parliamentary processes, and the reduced aggregative capacities of the democratic system, the possibilities for answering to diversified demands solely through parliamentary mechanisms are rather limited.

Following the logic of appropriateness, the political level is forced to strengthen the strategic agility and temporal capacity of the executive system, by adopting informal policy instruments and collaborative arrangements, which is followed by an increase in programs and temporary organizations working on top of permanent administrations and allowing for just-in-time interventions within open-ended processes. These actions, in turn, whether successful or not, affect our understanding of social problems and our demands for future actions. The complexities outlined in the previous section thus may have considerable effects on all three institutional pillars and, by consequence on the governability and legitimacy of the politico-administrative system. This turns us to the question of how and under what conditions governance can be a solution to the challenges of governability.

\section{Governance mechanisms as solutions to problems of}

\section{governability}

The challenges of governability outlined in the previous section have been the target of adopted governance strategies and administrative reforms in all Western democracies for the past several decades. However, the dependencies are multifarious and empirical evidence on the success or failure of such strategies is mixed, to say the least. Due to the aforementioned societal complexities, governance is essentially about striking a balance between desired, but potentially contending, values and objectives. Potentially, contending values pose tensions, which a governance system can manage to a greater or lesser degree, depending on, for 
example, adopted organizational forms, governance principles and policy instruments. Departing from the three institutional pillars summarized in the previous section, we would emphasize three such tensions, especially pertinent to complex institutional settings (Table 6.1). First, it is evident that the regulative dimension is strongly affected by the hybridization of contemporary governance systems. Hybridization is, above all, a reflection of the tension between flexibility and coordination. Many institutional elements of recent administrative reforms, targeted towards multi-scalar problems such as deregulation, soft law steering, budgetary reforms as well as creating networks and partnerships, are expected not only to be flexible but to also increase the cross-sectoral coordinative capacities within policy processes.

\section{[TS: Insert Table 6.1 here]}

Second, and pertaining to the normative foundations of contemporary societies, governability problems have had a considerable impact on our understanding of two fundamental organizing principles: competition and collaboration. In an increasingly hybridized context, possible contentions - but also putative tradeoffs - between interests and objectives come to a head, not least from the point of view of government institutions. While traditional resource dependency theory is concerned with patterns of contest, power and competition over scarce resources, the collaborative governance approach, in particular, emphasizes collaborative rather than competitive advantages, that is, potential synergistic gains of sharing resources (cf. Lowndes \& Skelcher, 1998, p. 317). Furthermore, collaborative governance arrangements are increasingly expected to be able to strike a balance between fundamental and potentially contending values, such as democracy and effectiveness. They are pursued in order to strengthen the democratic qualities of governance systems by means of participatory and deliberative procedures, while also contributing to effective policymaking.

As argued earlier, the cognitive dimension of institutions draws attention to the weakened aggregative capacities of democratic systems. In order to avoid the evident risk of 
further fragmentation due to the increase in the number of policy instruments, organizational alternatives and involved actors, there have been considerable efforts to increase the capacities of government institutions for metagoverning collaborative processes. This is a reflection of the third tension, that is, the traditional distinction between steering and rowing. Developments associated with New Public Management (NPM) emphasized the need for governments to 'steer not row', that is, make policies but engage other actors to deliver public services (Dahlström et al., 2011). However, recent developments have made the distinction almost meaningless; a number of actors are engaged in both steering and rowing. Organizations are increasingly multifunctional and a number of strategies can be applied depending on the situation. More essential for the role of public institutions, is their capacity for coordinating and facilitating multi-actor policy processes, not least by means of adapting the institutional and organizational design to the continuously changing policy conditions (cf. Jacobsson et al. 2015, p. 133). The mechanisms for managing these three fundamental tensions are further elaborated in the following sections.

\section{Governance Between Flexibility and Coordination}

The perceived rigidity of public sector institutions has, since the 1980 s, been a key target of public sector reform policies, not least the NPM reforms. The proliferation of nonbureaucratic organizational forms such as projects, partnerships, networks and contractual forms of cooperation are examples of means for increasing the problem-solving and coordinative capabilities of executive systems and for organizing vested interests, stakeholders and expertise on a just-in-time basis. 'The project', in particular, has become an organizational archetype not only for accelerated social problem-solving but also for decisiveness, innovation and entrepreneurship, to the extent that project proliferation has been taken into account for a projectification of politics and public sector activities (Godenhjelm et al., 2015; Jensen et al., 2013; Sjöblom et al., 2013). 
Since the financial crisis of the early 1990s there has, furthermore, been a constant need for increasing strategic agility (OECD, 2010) and for securing a flexible adaptation of the governance systems to external and internal challenges. Although the aim of reforms targeted towards deregulation, privatization, soft laws, partnerships and aggregated budget allocations has not necessarily been flexibility as such, they have contributed to more flexible solutions by giving government institutions an opportunity to exit their regulatory role and by providing more autonomy and budgetary discretion for agencies at operative administrative levels (Pierre, 2012, p. 192 ff.)

The neoliberal wave of the 1980s has also irreversibly strengthened the interventionist character of public policymaking, meaning that experimentation and evaluation have become integral parts of broader management doctrines such as performance management, partnership management and evidence-based management (Vedung, 2010, p. 263 f.). It is thus important to recognize that the changes in the aftermath of NPM have had a considerable influence on the ways in which interventions and time frames are constructed in public policies (cf. Pollitt, 2008, p. 26). In order to enhance strategic agility, flexible and collaborative actions and procedures are turned into an institutionalized standard for just-intime intervention (cf. Røvik, 2008). Flexibility is, in other words, perceived as a prerequisite for enhancing the adaptive and transformative capacities of government institutions.

The aforementioned developments should not, however, be interpreted only as a gradual move towards increasingly flexible and diverse institutional structures. First, institutional flexibility has, to a considerable extent, been achieved through a reliance on collaborative forms of governance rather than intra-organizational reforms (Pierre, 2012, p. 187). Second, the role of government institutions is still to ensure political and administrative authority, albeit in increasingly collaborative settings. The increase in informal policy instruments and non-bureaucratic forms of organizing are thus also expressions of the need for coordinative actions, both horizontally and vertically. The multifunctional and cross- 
sectoral nature of policy problems has emphasized the need for coordination, especially at central state level (Bouckaert et al., 2000). One consequence of the need for horizontal coordination has been the renaissance of planning and strategic development, to a considerable extent organized by means of programs, projects and informal working groups. The purpose is to provide flexible instruments for eliminating contradictions and tensions between different policies but also to provide a means for depoliticizing decisions by making them a matter of operational management (Sjöblom \& Godenhjelm, 2009). Programs, networks and working groups are established as inter-organizational and cross-sectoral instruments in order to provide political and administrative support for strategic initiatives (cf. Bouckaert et al., 2000).

In multi-level contexts the most obvious expression of the need for vertical coordination is perhaps the partnership principle, as implemented in the Cohesion policy of the EU and the Structural Fund policies. The EU develops framework programs in a wide branch of fields such as technological development, employment, prevention of marginalization, promotion of health and prevention of drug-related problems Thus, supranational policies force national administrations to adapt to the collaborative logic. National administrations have to facilitate large-scale collaboration for pursuing and integrating supranational, national, regional and local development objectives. Programs and partnerships have enabled a far broader spectrum of actors to become active in decision-making processes, thereby broadening the scope of strategic development. Following the concept of interactive policymaking (Klijn \& Koppenjan, 2003), the administration has to maximize political support for policies and minimize resistance by involving potential veto-groups in the process of policy formation. Moreover, projects have important functions in 'trickling down' global regulatory frameworks to locally implemented initiatives, thus providing the means for overcoming tensions between overarching policy frameworks and local implementation (Sjöblom, 2006; Sjöblom \& Godenhjelm, 2009). 
As these examples show, governance instruments are expected to provide flexible and efficient alternatives to traditional hierarchical methods of coordination in several ways. Horizontally, they are supposed to contribute to a greater coherence between policy areas and to provide cross-sectoral political and administrative support for strategic initiatives. In vertical terms, they are expected to incorporate stakeholders at various administrative levels in order to achieve synergetic advantages but also to eliminate conflict between key interests in implementation processes. The need for coordinative actions comes to a head in environmental management and sustainable resource use where needs for ongoing change and co-evolution with unfamiliar environmental conditions pose specific challenges to governance institutions. In complex institutional contexts, coordination is essentially about maintaining sufficient strategic connectivity between sectors and administrative levels in order to secure consistent policy design and implementation (cf. Lockwood et al., 2010, p. 995).

It is, however, important to recognize that flexibility cannot be equated to a general deformalization or deregulation. As argued by Pierre (2012), organizations need, on the one hand, to have the capacity to adapt to changes in the environment and to changing demand patterns. On the other hand, flexibility sits at odds with fundamental public sector values, such as due process, procedural fairness and equal treatment (Pierre, 2012, p. 197). In other words, there will always be a formal legal aspect to new governance arrangements. Stability and coordination should support policy coherence, while flexible instruments are associated with particularized solutions (Sjöblom \& Godenhjelm, 2009). The problem of finding the right balance is complicated by the multi-scalar nature of policy problems and by the multifunctionality of public sector institutions (Christensen \& Laegreid, 2013). These problems come to a head in devolved systems of governance, where coordinative action requires functioning and sufficiently resourced regional and local level institutions. Otherwise the nonbureaucratic forms of organizing may lack those coordinative potentials, thereby running the 
risk of enforcing rather than counteracting subnational diversities and variations (cf. Sjöblom \& Andersson, 2016).

\section{Governance Between Competition and Collaboration}

A key challenge for the normative foundations of contemporary governance systems is that of meeting increasingly diverse values and objectives. Systems are, furthermore, expected to be able to strike a balance between potentially contending sets of values (cf. Jacobsson et al., 2015, p. 7). New forms of co-governance and public policymaking, such as partnerships, democratic networks, projects and deliberative fora rely heavily on inclusive, collaborative and participatory strategies while also being expected to increase the effectiveness of decision-making processes. The growth of partnerships and other forms of collaborative arrangements also reflect the insight that the complexity of wicked issues facing governments only can be managed by bringing together the resources of a wide range of service providers and interest groups. Furthermore, collaborative approaches also recognize the role of norms of values in sustaining inter-organizational relationships over time (Lowndes \& Skelcher, 1998, p. 315).

In conceptual respects, the collaborative governance approach is multifarious in the sense that contemporary definitions rest on a number of hypothetical relationships in which desired consequences of the collaborative arrangements are strongly intertwined. This is partly due to the fact that collaborative governance can be perceived both as an approach for reconstructing democracy and as a technique for decision-making and policy implementation. If we, for instance following Ron's (2012, p. 472) definition, perceive democratic governance as 'attempts to institutionalize spaces for the expression of the voice of the people in situations where no single institution has the power to carry out its decisions", then the key question is to what extent these institutionalized spaces can be described as democratic and how should they be organized in order to contribute to the desired policy outcome. 
According to another frequently cited definition by Ansell and Gash (2008, p. 544), collaborative governance can be perceived as: A governing arrangement where one or more public agencies directly engage non-state stakeholders in a collective decision-making process that is formal, consensus-oriented and deliberative and that aims to make or implement public policy or manage public programs or assets.

Collaborative arrangements are here expected to strengthen the transformative capacities of the decision-making system, thereby enhancing efficient policy implementation. In its widest sense collaborative governance can thus be referred to as a strategy for 'reconstructing democracy along less adversarial and managerial lines' (Ansell, 2012, p. 498). A basic assumption of the collaborative governance approach is that relational and multi-actor forms of action - not only on the side of politics, but more importantly, at the policy level provide means for democratic reconstruction but also for more effective forms of policy implementation (e.g. Fung \& Wright, 2001; Hajer \& Wagenaar, 2004; Papadopoulos \& Warin, 2007; Sørensen, 2005).

In short, collaborative governance arrangements are, from an institutional point of view, expected to enhance capacity-building, that is, to strengthen the capacity for collective action, not least as a consequence of the devolution of power from central state institutions towards regional and local institutions (cf. Fischer, 2012, p. 460). Drawing on the literature, the extent to which collaborative arrangements can provide a solution to problems of governability in politico-administrative systems is dependent on at least three broad sets of factors: a) the structural design and relational activities of the collaborations; b) contextual dependencies and; c) functioning intersections between government institutions and collaborative structures.

As for the structural design of collaborations, it is important to note that collaborative governance approaches - as indicated by the aforementioned definitions - deviate from the traditional resource dependency theory by emphasizing the notion of synergistic gain and 
program enhancement from sharing resources and risks, thus prioritizing collaborative rather than competitive advantages (Lowndes \& Skelcher, 1998, p. 317). There is a considerable body of research showing that, for example, natural resource governance can benefit from actors agreeing on common rules and practices and from building common knowledge (Carlsson \& Berkes, 2005; Gardiner et al., 1990). But comprehensive reviews of the literature also indicate that no structural characteristics such as density of relations, degree of cohesiveness or interconnectivity between actors present a monotonically increasing positive effect on processes of importance for resource governance. Favoring one characteristic is likely to occur at the expense of others (Bodin \& Crona, 2009, p. 366).

This appears to be the case also with respect to relational and participatory actions of collaborations. The governance debate has expressed particularly strong expectations of the democratic impact related to virtually all of the key mechanisms of the democratic system, that is, representation, participation and deliberation. From a representative point of view collaborative governance arrangements are expected to provide means for more legitimate governmental action. In terms of participation, collaborative governance has been emphasized as a response to a democratic deficit, characteristic of contemporary political systems. The concept emerged in the 1990s through a multiplication of existing kinds of participatory arrangements, that is, as a way of establishing new spaces for civil society actors and enabling various combinations of virtually all kinds of participatory activities. Joint responsibility and a sense of ownership among the participating actors would be beneficial with respect to policy implementation through a decrease in conflicts and implementation resistance (Hajer \& Wagenaar, 2003b, pp. 10-13; Sørensen \& Torfing, 2007a, p. 13). A deliberative approach to collaborative governance, finally, is emphasized on consensualism, negotiation and joint problem-solving. The deliberative process leads to the 'ennoblement' of original opinions and according to the ideal interpretation, to a mutual understanding and consensus. The deliberative process, which is based on the evaluation of arguments rather 
than the representation of interests, is expected to generate a greater acceptance of the outcome for the actors involved (Teorell, 2006, p. 797).

It is, however, obvious that structural as well as relational and participatory qualities may interact in ways that are either favorable or detrimental with respect to substantive outcomes of collaborations. This is due to the fact that each institutional order, be they government institutions, markets, professions or corporations, operates according to specific institutional logics in the sense that they represent unique values, symbols, and organizing principles that might reinforce or counteract change (cf. Thornton et al., 2012, p. 2). In order to explain any action, one has to take into account not only the objective conditions, but also the actor's subjective interpretations of them, that is, conceptions of the preferred and desirable as well as perceptions of how things should be done (Scott, 2008, p. $54 \mathrm{ff}$. ). In a public context the relationship between governmental and non-governmental institutions is of particular importance. Government institutions on the one hand, and private and third sector organizations on the other, operate according to very diverse institutional logics (Sjöblom \& Andersson, 2016). In terms of capitalizing on and sustaining the outcomes of public sector collaborations, many findings point to the importance of specific mediating and facilitating mechanisms, such as overlapping memberships and effective procedures for knowledge transfer in the intersection between administrative and collaborative structures (Godenhjelm, 2016; Godenhjelm \& Johanson, 2015; Sjöblom et al., 2012).

Finally, it should be taken into account that all the aforementioned dependencies are contextually sensitive. Approaches to collaborative governance rely heavily on a widening of the distribution of resources through enforced interactions between state and non-state actors. The potential of cross-sector collaborations vary, not only depending on the explicit motives of the involved actors, but also due to confrontations between the different rationales, traditions and procedures that the actors represent. The term 'collaborative governance' is a generic one, encompassing a wide range of sector-specific procedures and 
techniques, such as collaborative planning, various arrangements for natural resource governance and regulatory negotiation (cf. Ansell, 2012, p. 500). The possibilities for achieving the most favorable level where the positive effects of collaborative interactions are obtained, while undesired effects are minimized, have to be assessed in the respective context of the collaborative arrangements in question (cf. Bodin \& Crona, 2009, p. 372). Furthermore, administrative traditions and pre-existing relations matter. Studies of, for instance, cohesion policy implementation have shown that there are considerable differences both between and within states regarding substantive outcomes of collaborative arrangements (Bache, 2012; Hooghe, 1996; Sjöblom \& Andersson, 2016). Despite many similarities between countryspecific reform agendas and general developments towards collaborative governance structures, subnational governance in Europe has not become predominantly homogenized and, what is more important, there are considerable and growing tendencies towards diversity within single states (Hendricks, Loughlin and Lidström, 2011 pp. 728-30).

Effective collaborative arrangements in diverse institutional contexts are thus essentially a matter of balancing between different and contextually sensitive structural and relational characteristics of collaborations and of mediating between potentially contending institutional logics. The collaborative ideal represents strong synergetic potentials but collaborations also run the risk of contributing to diversity and fragmentation due to competing values and interests among involved actors and a lack of facilitating mechanisms in the interface between politico-administrative and collaborative structures.

\section{Between Steering and Rowing: Metagovernance as an}

\section{Integrative Solution?}

Collaborative governance arrangements are highly dynamic and contingent phenomena. The possibilities for striking a balance between potentially contending demands and values are contextually sensitive. As argued earlier, flexible governance structures may, furthermore, 
enhance diversities and fragmentation rather than coordination. These tensions derive from the fact that collaborative arrangements rest on multiple sources of legitimacy. The source can be a mandate given by elected institutions but also contractual arrangements with nonelected institutions or the direct involvement of citizens (cf. Ansell, 2012). Moreover, the state is increasingly characterized by international as well as domestic embeddedness. On the one hand, the integration between the state and international organizations generates norms and directives, which require domestic compliance. On the other hand, government institutions are dependent on voluntary cooperation with autonomous actors causing needs to induce non-state societal partners to cooperate (Jacobsson et al., 2015, p. 2).

It is clear that the continuous need for transformative reforms with regard to the resilience of the society will have far-reaching consequences for the future role of the political system in general and public sector institutions in particular. Public agencies are increasingly perceived as agents for renewal and change. Through partnerships and cooperation they are expected to take a more active role in providing favorable settings for reform initiatives, innovation and new growth. According to current reform strategies, the public sector should, furthermore, undertake reforms of operating methods, legislation and competence, thereby heading for broad-based cooperation and stronger incentives for innovation (cf. Research and Innovation Policy Council, 2015). In governance theory, favorable restructuring and innovation is frequently perceived as conditional on the institutional and collaborative capacity of involved actors. There are, however, still considerable ambiguities concerninghe specific institutional prerequisites favoring a long-term sustaining of innovation and change, particularly in a public context. The problem with the programmatic reform strategy is that it tends to treat the state as a monolithic entity (cf. Jacobsson et al., 2015, p. 20). From an empirical point of view public institutions have, however, moved towards diversity. Due to differences in resources, organizational cultures and traditions, the possibilities for 
government institutions to fulfill their role as agents for change and innovation vary considerably.

More specifically, government institutions face a twofold problem. First, they have to secure the cornerstone of democratically legitimate government, that is, the principle of authorization, according to which those producing collectively binding decisions should be authorized ex ante, through elections, on behalf of those subject to the decisions (Papadopoulos, 2012, p. 514). Second, government institutions are forced to strengthen coordination because the aim of collaborative instruments such as programs, projects and partnerships is partly to reinforce the problem-solving capacity by means of partitioning, that is, the aforementioned reliance on temporary organizations in order to enhance the strategic agility of permanent structures, as well as their capacities for just-in-time planning and intervention.

The solution to the authorization and coordination problems offered by the governance concept is that of metagovernance, that is, an active role of state institutions and agencies in coordinating, facilitating and managing multi-actor policy processes without reverting to traditional forms of command and control (Kickert et al., 1997; Torfing, 2012, p. 107). Government institutions can, to a varying extent, design the collaborative processes and be in charge of their management (Papadopoulos, 2012, p. 515).

The problem with the metagovernance concept is, however, that it has sought to define the governance role of the state in relation to governance networks, thus overlooking the capacity of the government to organize governance and to operate successfully within the parameters set by collaborative governance structures (Jacobsson et al., 2015, p. 4). Recent accounts have criticized the concept with respect to these shortcomings and argued that theories on governance should be supplemented by a stronger theoretical focus on the inner workings of government organizations in complex contexts. In order to enhance agency, renewal and change, government institutions cannot solely facilitate at arm's length or by 
following a hands-off strategy; neither can they restrict their role to a collaborative actor, among others. Thus the metagovernance concept does not only include mechanisms for steering and coordination in a conventional sense. Especially in an embedded context, the concept also denotes steering through institutional design, that is, steering by organizing and by creating endogenous processes of coordination and rule-following, thereby strengthening the capacities for legitimate governmental action (cf. Jacobsson et al., 2015, p. 133).

Based on the current state of the art there are at least three sets of determinants that appear particularly salient in terms of metagoverning innovative actions. Government institutions have, first, to enhance trust in coordinated and innovative processes (i.e. values that support innovation processes), while conversely, stability and reproduction of values and norms in times of policy changes or changes in the external environment will pose considerable problems to the renewal of innovation processes (cf. Jacobsson et al., 2015, p. 131). Each institutional order, be they government institutions, markets, professions or corporations, represent unique values, symbols, and organizing principles that might reinforce or counteract change and innovation (cf. Thornton et al., 2012, p. 2).

Second, government institutions should be able to metagovern the processes by affecting the institutional design in ways that support the desired direction of change. This perception of change emphasizes governing by organizing, that is, changing institutional jurisdictions and autonomy, structural forms of organizing, tasks and resources of involved agencies (cf. Jacobsson et al., 2015, p. 130; Sørensen, 2006). It is important to recognize that actors within specific policy fields are increasingly embedded in, and dependent on, the EU as well as national structures through policy programs that provide prescriptions not just on what should be achieved (policy prescriptions) but also how they should do it (governance and management prescriptions) (cf. Jacobsson et al., 2015, p. 132). Public-private partnerships are forced to meet these prescriptions, which are particularly salient in the field of innovation policies. The institutional embeddedness is reinforced by developments 
witnessed in many countries in the aftermath of NPM reforms, decentralization and devolution, in order to strengthen authority and to increase the means for control by the core executive (Christensen \& Laegreid, 2013; Jacobsson et al., 2015). The continuous need for organizing and reorganizing is currently, not least in Finland, reflected in the continuous and sequential reform processes present at all administrative levels.

Third, government institutions are expected to facilitate the micro-level implementation of policies, that is, to enhance the capacity for change of individual agencies and collaborating actors within the partnerships, projects and networks through which individual policies are implemented, thereby also facilitating the long-term utilization and consolidation of specific changes. Micro-level facilitation is pursued by means of, for example, information, participatory procedures, collaborative practices and evaluation.

Existing empirical evidence on the inclination and willingness of government institutions to play the collaborative game are mixed and relatively scarce. There are indications that network involvement is positively related to social outcomes but also that such effects are contingent on local and sectoral conditions (Ansell, 2012; Papadopoulos, 2012). Studies presented in the special issue of the Scandinavian Journal of Public Administration (2013) show that the state, at least in a Nordic context, reacts to dynamic forces by striving towards stability. Securing political attention and integrating collaborative actions into overarching policies appear to be central factors for explaining project success. The studies illustrate the delicate balance between over-institutionalization in order to simultaneously secure coherence and synchronized activities and a high degree of autonomy for pursuing the experimental, innovative and decision-making qualities usually associated with collaborative organizational forms (Sjöblom et al., 2013, p. 7). 


\section{Conclusion}

Governance approaches can have considerable impacts on virtually all key institutional dimensions of the politico-administrative system. The governance arrangements and mechanisms scrutinized in the previous sections of this chapter have strong potential in terms of enhancing governability, interpreted as the overall capacity for governance of a societal entity or system. However, all governance arrangements also have potentially detrimental consequences (Table 6.2). First, the adoption of informal policy instruments and policy implementation by means of increasingly multifunctional organizations requires coordinative resources and capacities of national, as well as subnational, institutions. Otherwise, such instrumentsmay contribute to increasingly varied developments, both in terms of policy implementation practices and structural developments at regional and local levels. Second, the synergetic capacities of collaborative approaches are highly dependent on the structural design of the collaborations but also of facilitating mechanisms in the interface between government, markets and civil society. For avoiding tendencies of fragmentation, collaborative arrangements in diverse institutional contexts require balancing between different and contextually sensitive structural and relational characteristics of collaborations and of mediating between potentially contending institutional logics. Third, metagoverning collaborative structures requires that government institutions have capacities for affecting the institutional design of collaborative actions and for facilitating micro-level collaborative policy implementation. The metagovernance concept is characterized by an inherent tension in terms of institutionalizing collaborative procedures on the one hand, while providing sufficient autonomy for strategic and innovative actions on the other.

\section{[TS: Insert Table 6.2 here]}


It is, as argued earlier, important to recognize that no structural characteristics of collaborative actions present a monotonically increasing positive effect on processes of governing. Nor are governance mechanisms, such as informal policy instruments, collaborative arrangements and procedures for metagovernance necessarily mutually reinforcing. Governability and adaptive capacities in complex institutional contexts is essentially a matter of knowledge utilization, learning and experimentation and an orientation towards the long term (cf. Lockwood et al., 2010, p. 989). This is the case especially in policy fields like environmental management, natural resource governance and regional development. Yet it is important to bear in mind that collaborative governance arrangements conducive to desirable forms of learning and innovation may also have unintended and perhaps undesired consequences (cf. Lewis \& Triantafillou, 2012). Projects, partnerships and networks are expected to provide flexibility and alternative solutions for instant action, thus putting pressure on public managers and politicians in terms of selecting between available alternatives. While the governability concept in the 1970s and 1980s was preoccupied with a purported overload in expectations, demands and public tasks, that is, the input side of the policy cycle, contemporary governance arrangements run the risk of creating overload in terms of outputs. To put it differently: The problem may be an abundance rather than a lack of alternative pathways and actions.

An important prerequisite for successful collaborations is, furthermore, that there are genuinely mutual dependencies and incentives between the involved actors, that is, a significant degree of reciprocity and mutual support between key actors of collaborative structures: government institutions, markets and civil society, supported by a collaborative vision and sustained political leadership on the part of government (Phillips, 2012, p. 492). Government institutions have to be able to fulfill traditional administrative roles while simultaneously strengthening their collaborative and facilitating capacities in increasingly emergent policy fields. From a governability point of view, it thus appears evident that the 
future research agenda on sustainability issues and natural resource management should include a focus on:

- The tensions between bureaucratic and collaborative ideals and the consequences of such tensions in long-term decision-making and open-ended processes;

- Mediating and facilitating mechanisms in the intersection between administrative and collaborative structures;

- The mechanisms for maintaining strategic connectivity between policy sectors and administrative levels in order to secure consistent policy design and implementation;

- Comparative analyses of contextual impacts on the outcome of collaborative arrangements;

- The capacities of government institutions for facilitating the micro-level implementation of policies in collaborative settings; and

- Undesired consequences of collaborative governance arrangements, particularly the risk of generating overload of alternatives solutions and actions at the output side of the policy cycle.

As these themes indicate, finding the right balance between key governance parameters in complex institutional settings is no one-off event. It is increasingly a matter of continuous adjustments in open-ended processes.

\section{References}

Adam, B. (1995) Timewatch: The Social Analysis of Time. Polity Press, Cambridge. 
Allan, C. \& Curtis, A. (2005) Nipped in the Bud: Why Regional Scale Adaptive Management Is Not Blooming. Environmental Management, 36(3) pp. 414-425.Amin, A. (1999) An Institutionalist Perspective on Regional Economic Development. International Journal of Urban and Regional Research, 23(2) pp. 365-378.

Ansell, C. (2012) Collaborative Governance. In: Levi-Faur, D. (Ed.), The Oxford Handbook of Governance. Oxford University Press, New York.

Ansell, C. \& Gash, A. (2008) Collaborative Governance in Theory and Practice. Journal of Public Administration Research and Theory, 18(4) pp. 543-571.

Bache, I. (2012) Multi-level Governance in the European Union. In: Levi-Faur, D. (Ed.), The Oxford Handbook of Governance. Oxford University Press, New York.

Bodin, Ö. \& Crona, B.I. (2009) The Role of Social Networks in Natural Resource Governance: What Relational Patterns Make a Difference? Global Environmental Change, 19(3) pp. 366374.

Bouckaert, G., Ormond, D. \& Peters, G. (2000) A Potential Governance Agenda for Finland. Ministry of Finance, Research Reports 8/2000, Helsinki.

Burger, M., van der Knaap, B. \& Wall, R.S. (2014) Polycentricity and the Multiplexity of Urban Networks. European Planning Studies 22:4, pp. 816-840.

Carlsson, L. \& Berkes, F. (2005) Co-management: Concepts and Methodological Implications. Journal of Environmental Management, 75(1) pp. 65-76.

Charron, N. (2013) QoG at the Sub-national Level and the EQI. In: Carron, N., Lapuente, V. \& Rothstein, B. (Eds.), Quality of Government and Corruption from a European Perspective. Edward Elgar Publishing Ltd, Cheltenham. 
Christensen, T. \& Laegreid, P. (2013) Introduction. In: Christensen, T. \& Laegreid, P. (Eds.), The Ashgate Research Companion to New Public Management. Ashgate Publishing Company, Burlington.

Crozier, M., Huntington, S.P. \& Watanuki, J. (1975) The Crisis of Democracy: Report on the Governability of Democracies to the Trilateral Commission. New York University Press, New York.

Dahlström, C., Peters, B.G. \& Pierre, J. (2011) Steering from the Centre. Strengthening Political Control in Western Democracies. University of Toronto Press, Toronto.

Dennis, K. (2007) Time in the Age of Complexity. Time \& Society, 16(3) pp. 139-155.

DiMaggio, P.J. \& Powell, W. (1991) Introduction. In: DiMaggio, P.J. \& Powell, W. (Eds.), The New Institutionalism in Organizational Analysis. University of Chicago Press, Chicago.

Dryzek, J. (1987) Rational Ecology: Environment and Political Economy. Blackwell, Oxford.

Fischer, F. (2012) Participatory Governance: From Theory to Practice. In: Levi-Faur, D. (Ed.), The Oxford Handbook of Governance. Oxford University Press, New York.

Fung, A. \& Wright, E.O. (2001) Deepening Democracy: Innovations in Empowered Participatory Governance. Politics \& Society, 29(1) pp. 5-41.

Gardiner, R., Ostrom, E. \& Walker, J.M. (1990) The Nature of Common-Pool Resource Problems. Rationality and Society, 2(3) pp. 335-358.

Godenhjelm, S. (2016) Project Organisations and Governance: Processes, Actors, Actions, and Participatory Procedures. University of Helsinki, Faculty of Social Sciences, Department of Economic and Political Studies, Helsinki. 
Godenhjelm, S. \& Johanson J-E. (2018) The Effect of Stakeholder Inclusion on Public Sector Project Innovation. International Review of Administrative Sciences, 84(3) August, 0020852315620291 , first published on March 14, 2016.

Godenhjelm, S., Lundin, R.A., \& Sjöblom, S. (2015) Projectification in the Public Sector: The Case of the European Union. International Journal of Managing Projects in Business, 8(2) pp. 324-348.

Hajer, M. \& Wagenaar, H. (2003) Introduction. In: Hajer, M. \& Wagenaar, H. (Eds.), Deliberative Policy Analysis. Understanding Governance in the Network Society. Cambridge University Press, Cambridge.

Hendricks, F., Loughlin, J. \& Lidström, A. (2011) European Subnational Democracy: Comparative Reflections and Conclusions. In: Hendricks, F., Loughlin, J. \& Lidström, A. (Eds.), The Oxford Handbook of Local and Regional Democracy in Europe. Oxford University Press, New York.

Hooghe, L. (1996) Cohesion Policy and European Integration. Building Multi-level Governance. Oxford University Press, Oxford.

Jacobsson, B., Pierre, J. \& Sundström, G. (2015) Governing the Embedded State. The Organizational Dimension of Governance. Oxford University Press, Oxford.

Jensen, C., Johansson, S. \& Löfström, M. (2013) The Project Organization as a Policy Tool in Implementing Welfare Reforms in the Public Sector. The International Journal of Health Planning and Management, 28(1) pp. 122-137.

Kickert, W.J.M., Klijn, E-H. \& Koppenjan, J.F.M. (1997) Introduction: A Management Perspective on Policy Networks. In: Kickert, W.J.M., Klijn, E-H. \& Koppenjan, J.F.M. (Eds.), Managing Complex Networks. Strategies for the Public Sector. Sage, London. 
Klijn, E-H. \& Koppenjan, J.F.M. (2003) Rediscovering the Citizen: New Roles for Politicians in Interactive Policy Making. In: McLaverty, P. (Ed.), Public Participation and Innovations in Community Governance. Ashgate, Aldershot.

Kooiman, J. (2008) Exploring the Concept of Governability. Journal of Comparative Policy Analysis: Research and Practice, 10(2) pp. 171-190.

Laux, H. (2011) The Time of Politics: Pathological Effects of Social Differentiation. Time and Society, 20(2) pp. 224-240.

Lewis, J.M. \& Triantafillou, P. (2012) From Performance Measurement to Learning: A New Source of Government Overload? International Review of Administrative Sciences, 78(4) pp. $597-614$.

Lockwood, M., Davidson, J., Curtis, A., Stratford, E. \& Griffith, R. (2010) Governance Principles for Natural Resource Management. Society \& Natural Resources 23(10) pp. 986-1001.

Loorbach, D. (2010) Transition Management for Sustainable Development: A Prescriptive, Complexity-based Governance Framework. Governance, 23(1) pp. 161-183.

Lowndes, V. \& Skelcher, C. (1998) The Dynamics of Multi-organizational Partnerships: An Analysis of Changing Modes of Governance. Public Administration, 76(2) pp. 313-333.

Mayntz, R. (1993) Governing Failures and the Problem of Governability: Some Comments on a Theoretical Paradigm. In: Kooiman, J. (Ed.), Modern Governance. Sage, London.

Meadowcroft, J. (2013) Sustainable Development. In: Bevir, M. (Ed.), The SAGE Handbook of Governance. Sage, London.

Norris, P. (2011) Democratic Deficit: Critical Citizens Revisited. Cambridge University Press, New York. 
OECD (2010) Public Administration After 'New Public Management'. OECD, Paris.

Papadopoulos, Y. (2012) The Democratic Quality of Collaborative Governance. In: Levi-Faur, D. (Ed.), The Oxford Handbook of Governance. Oxford University Press, New York.

Papadopoulos, Y. \& Warin, P. (2007) Are Innovative, Participatory and Deliberative Processes in Policy Making Democratic and Effective? European Journal of Political Research, 46(4) pp. 445-472.

Phillips, S.D. (2012): The New Citizenship and Governance: Alternative Intersections. In: LeviFaur, D. (Ed.), The Oxford Handbook of Governance. Oxford University Press, New York.

Pierre, J. (2012) Governance and Institutional Flexibility. In: Levi-Faur, D. (Ed.), The Oxford Handbook of Governance. Oxford University Press, New York.

Pollitt, C. (2008) Time, Policy, Management. Governing with the Past. Oxford University Press, New York.

Research and Innovation Policy Council (2015) Reformative Finland: Research and Innovation Policy Review 2015-2020. Research and Innovation Policy Council, Helsinki.

Rhodes, R.A.W. (1996) The New Governance: Governing Without Government. Political Studies, 44(4) pp. 652-667.

Ron, A. (2012) Modes of Democratic Governance. In: Levi-Faur, D. (Ed.), The Oxford Handbook of Governance. Oxford University Press, New York.

Røvik, K.A. (2008) Managementsamhället. Trender och idéer på 2000-talet. Liber, Malmö. 
Scandinavian Journal of Public Administration (2013) Special Issue: Projectified Politics. The Role of Temporary Organisations in the Public Sector, 17(2).

Schneider, V. (2012) Governance and Complexity. In: Levi-Faur, D. (Ed.), The Oxford Handbook of Governance. Oxford University Press, New York.

Scott, R.W. (2008) Institutions and Organizations. Sage, Thousand Oaks.

Sjöblom, S. (2006) Introduction: Towards a Projectified Public Sector: Project Proliferation as a Phenomenon. In: Sjöblom, S., Andersson, K., Eklund, E. \& Godenhjelm, S. (Eds.), Project Proliferation and Governance: The Case of Finland. SSKH Meddelanden 69. Swedish School of Social Science, University of Helsinki, Helsinki.

Sjöblom, S. \& Andersson, K. (2016) The Prospects for Bridging Spatial and Institutional Divides Between Regions: Rural-Urban Relationships in a Projectified Governance Context. In: Andersson, K., Sjöblom, S., Granberg, L., Ehrström, P. \& Marsden, T. (Eds.), Metropolitan Ruralities. Emerald Publishing Group Ltd.

Sjöblom, S. \& Godenhjelm, S. (2009) Project Proliferation and Governance - Implications for Environmental Management. Journal of Environmental Policy \& Planning, 11(3) pp. 169-185.

Sjöblom, S., Andersson, K., Marsden T. \& Skerratt, S. (Eds.) (2012) Sustainability and ShortTerm Policies. Improving Governance in Spatial Policy Interventions. Ashgate, Aldershot.

Sjöblom, S., Löfgren, K. \& Godenhjelm, S. (2013) Projectified Politics: Temporary Organizations in a Public Context. Introduction to the Special Issue. Scandinavian Journal of Public Administration, 17(2) pp. 3-12.

Sørensen, E. (2005) The Democratic Problems and Potentials of Network Governance. European Political Science, 4(3) pp. 348-357. 
Sørensen, E. \& Torfing, J. (2007) Introduction: Governance Network Research: Towards a Second Generation. In: Sørensen, E. \& Torfing, J. (Eds.), Theories of Democratic Network Governance. Palgrave Macmillan, Basingstoke.

Teorell, J. (2006) Political Participation and Three Theories of Democracy: A Research Inventory and Agenda. European Journal of Political Research, 45(5) pp. 787-810.

Thornton, P.H., Ocasio, W. \& Lounsbury, M. (2012) The Institutional Logics Perspective: A New Approach to Culture, Structure, and Process. Oxford University Press, Oxford.

Torfing, J. (2012) Governance Networks. In: Levi-Faur, D. (Ed.), The Oxford Handbook of Governance. Oxford University Press, New York.

Vedung, E. (2010) Four Waves of Evaluation Diffusion. Evaluation, 16(3) pp. 263-277. 